\title{
Lifting the veil: richness measurements fail to detect systematic biodiversity change over three decades
}

\author{
Stefano Larsen (iD,${ }^{1,2,6}$ Jonathan M. Chase, ${ }^{3,4}$ Isabelle Durance, ${ }^{5}$ and Steve J. Ormerod ${ }^{5}$ \\ ${ }^{1}$ University of Trento, Via Mesiano 77, Trento 38123, Italy \\ ${ }^{2}$ Synthesis Centre (sDiv) of the German Centre for Integrative Biodiversity Research (iDiv), Halle-Jena-Leipzig, Deutscher Platz 5 e, \\ Leipzig, Germany \\ ${ }^{3}$ German Centre for Integrative Biodiversity Research (iDiv), Halle-Jena-Leipzig, Deutscher Platz 5e, Leipzig, Germany \\ ${ }^{4}$ Department of Computer Sciences, Martin Luther University, Halle, Germany \\ ${ }^{5}$ Water Research Institute, Cardiff School of Biosciences, Cardiff University, Cardiff CF10 3 AX, United Kingdom
}

\begin{abstract}
While there is widespread recognition of human involvement in biodiversity loss globally, at smaller spatial extents, the effects are less clear. One reason is that local effects are obscured by the use of summary biodiversity variables, such as species richness, that provide only limited insight into complex biodiversity change. Here, we use $30 \mathrm{yr}$ of invertebrate data from a metacommunity of 10 streams in Wales, UK, combined with regional surveys, to examine temporal changes in multiple biodiversity measures at local, metacommunity, and regional scales. There was no change in taxonomic or functional $\alpha$-diversity and spatial $\beta$-diversity metrics at any scale over the 30 -yr time series, suggesting a relative stasis in the system and no evidence for on-going homogenization. However, temporal changes in mean species composition were evident. Two independent approaches to estimate species niche breadth showed that compositional changes were associated with a systematic decline in mean community specialization. Estimates of species-specific local extinction and immigration probabilities suggested that this decline was linked to lower recolonization rates of specialists, rather than greater local extinction rates. Our results reveal the need for caution in implying stasis from patterns in $\alpha$-diversity and spatial $\beta$-diversity measures that might mask non-random biodiversity changes over time. We also show how different but complementary approaches to estimate niche breadth and functional distinctness of species can reveal long-term trends in community homogenization likely to be important to conservation and ecosystem function.
\end{abstract}

Key words: functional diversity; homogenization; spatial scale; species specialization; species traits; temporal beta-diversity.

\section{INTRODUCTION}

Anthropogenic environmental change is linked unequivocally to rapid rates of species extinction globally (Butchart et al. 2010, Barnosky et al. 2011, Pimm et al. 2014). However, the link between global extinctions and changes in local assemblages remains uncertain. Some recent metaanalyses of long-term monitoring data have revealed that local-scale biodiversity has been relatively stable over the last decades (Vellend et al. 2013, Dornelas et al. 2014), or even increasing in some circumstances (Elahi et al. 2015). Although controversial (Cardinale et al. 2018, Primack et al. 2018), these analyses suggest that trends in local richness may be decoupled from global biodiversity loss.

One particularly important limitation in the interpretation of biodiversity change derives from the fact that most analyses typically focus on local species richness (i.e., the number of species at a given focal extent; Hillebrand et al. 2017). This measure does not account for changes in the composition of species and relative population densities (Supp and Ernest 2014), and is highly sensitive to sample grain and extent (Chase and Knight 2013). Any such analysis based only on one metric at just one spatial scale, and in the

Manuscript received 31 October 2017; revised 30 January 2018; accepted 2 March 2018. Corresponding Editor: Mark Christopher Urban.

${ }^{6}$ E-mail: larsen.stefano@gmail.com absence of compositional and/or functional information, risks failing to detect important biodiversity trends and their drivers (e.g., McGill et al. 2015).

To date, few studies have assessed long-term changes in multiple biodiversity measures across varying spatial scales, reflecting the scarcity of appropriate data. Those data that are available have revealed every possible combination of change, including stasis at multiple scales despite species turnover (e.g., Brown et al. 2001), increases or decreases at smaller, but not at larger scales (Keil et al. 2012, BernhardtRoemermann et al. 2015), and consistent changes across scales (e.g., Eskildsen et al. 2015, Harrison et al. 2015). Ultimately, the processes involved reflect the balance between species extinctions and colorizations through time, which interact and vary across extents to manifest as different trajectories of change (Sax and Gaines 2003).

Differences in biodiversity trends at different spatial extents must imply a change in species composition across localities (Cassey et al. 2006, McGill et al. 2015). For this reason, community composition is likely to be a more sensitive measure of biodiversity change than taxonomic richness (Brown et al. 2001, Dornelas et al. 2014). This is because the apparent stasis in taxonomic richness could occur irrespective of large compositional changes whenever the rates of local extinction and immigration compensate each other (Hillebrand et al. 2017). In addition, local changes in composition might not reflect just stochastic species 
redistribution across locations, but could be more systematic, potentially leading to biotic homogenization where common taxa become more widespread and/or rare taxa are lost (Olden 2006). Localities within a region would thus become increasingly similar in taxonomic composition, resulting in lower spatial $\beta$-diversity and potentially higher richness loss at larger spatial scales (e.g., Villeger et al. 2011).

In addition to taxonomic measures, many authors have emphasized how functional measures based on species traits can reflect local environmental conditions and eventually serve as an important indicator of biodiversity change (e.g., Townsend and Hildrew 1994). Such trait-based assessments have revealed how functional changes can occur within communities even in the absence of major changes in taxonomic richness (e.g., Monnet et al. 2014, Lindenmayer et al. 2015). Trait studies have also revealed how functional homogenization, the process by which communities in a region become increasingly similar in terms of functional traits, can occur independently of taxonomic homogenization (Villeger et al. 2014). However, studies like these that simultaneously assess changes in both taxonomic and functional dissimilarity among assemblages remain rare and are mostly focused on terrestrial organisms (e.g., Baiser and Lockwood 2011, Sonnier et al. 2014).

The use of species life-history traits is particularly well developed in freshwater ecosystems following important applications of the habitat templet landscape filtering theory to running waters (Townsend and Hildrew 1994, Poff 1997). Stream ecosystems are among the most sensitive ecosystems to anthropogenic disturbance (Dudgeon et al. 2006) and they support species-rich communities characterized by some of the most rapid rates of extinction on Earth (Ricciardi and Rasmussen 1999). In Europe, for instance, current projections of climate change predict a decrease in the extent of suitable areas for $\sim 40 \%$ of the modelled invertebrate species (Domisch et al. 2013). Further examinations of longterm biodiversity trends in river invertebrates are clearly needed, but appropriate data sets remain scarce (Ormerod and Durance 2009, Floury et al. 2017).

Here, we argue that a thorough assessment of biodiversity change should include analyses at multiple spatial scales, include measures of taxonomic diversity, functional diversity, and homogenization, and extend over sufficient time scales to distinguish trends from short-term variations (Hillebrand et al. 2017). In addition, since changes in biodiversity are ultimately driven by local species colonization and extinction, an appraisal of which species-level traits predict background probabilities of colonization and extinction could provide additional insights into the causes of any change (Gotelli and Taylor 1999). To illustrate these arguments and show how alternative measures of biodiversity can depict different trajectories of change, we analysed a unique data set of stream invertebrates collected at multiple spatial scales over three decades. Specifically, we focused on macroinvertebrates from a set of 10 streams in Wales, UK monitored annually for a period of $\sim 30 \mathrm{yr}$. Over the same period, we analysed larger-scale patterns from three Waleswide surveys of 58 streams that form the core of the Welsh Acid Water Survey (Ormerod et al. 1987). We show how the apparent stasis in many commonly used diversity measures can still be accompanied by non-random functional changes over time.

\section{Methods}

\section{Study area and biological data}

The Llyn Brianne Experimental Catchments and Stream Observatory cover $\sim 300 \mathrm{~km}^{2}$ in upland Wales $(210-410 \mathrm{~m}$ above sea level) in the upper reaches of the Afon Tywi $\left(52^{\circ} 8^{\prime} \mathrm{N} 3^{\circ} 45^{\prime} \mathrm{W}\right)$. The climate is maritime and temperate with mean stream temperature within $0-16^{\circ} \mathrm{C}$ and mean precipitation of $1,900 \mathrm{~mm} / \mathrm{yr}$. The streams are perennial and drain either sheep-grazed grassland or conifer forests. Stream macroinvertebrates at Llyn Brianne were collected yearly since 1981, with few exceptions, using identical, quality-checked methods, which were proven reliable for detecting differences in assemblages across streams and years (Bradley and Ormerod 2002). Samples were collected in April using standardized kick samples of 3-min duration, aggregated between riffle and marginal habitats, using a hand net $(0.9 \mathrm{~mm}$ mesh; $230 \times 255 \mathrm{~mm})$. The 10 headwater streams included in the analyses were selected out of the 14 available since they represented the best combination of spatial and temporal extent (Appendix S1: Fig. S1; Ormerod and Durance 2009). These streams also cover a wide range of physical-chemical conditions (acidic to neutral) and landuse types present in the area. Throughout the paper, we refer to these 10 streams as a metacommunity, since taxa regularly disperse among them over the short distances involved (Masters et al. 2007), and the streams have responded consistently to supra-catchment factors (e.g., climate) that transcend local influences (Bradley and Ormerod 2001). Macroinvertebrate data were available from 1984 to 2013, but five years were excluded in which not all streams were sampled (1991, 1993, 2008, 2009, 2011). Invertebrates were identified to species, except Diptera (family), Oligochaeta (class), and some Coleoptera (family).

\section{Regional monitoring data}

Identical methods were used to collect macroinvertebrates from 58 upland streams during the Welsh Acid Waters Survey (Ormerod et al. 1987) in 1984, 1995, and 2012, and these data were used to assess regional-scale trends. The complete regional data set allowed analyses only of presence-absence data and thus incidence data were used in the analyses for consistency. Nonetheless, abundance data were available for the 10 Llyn Brianne streams and we show that the main conclusions of the study hold when analyses included abundance patterns.

Stream physical-chemical characteristics were measured from regional surveys in 1984 and 1995 and these data were used to calculate species observed niche breadths (see below and Appendix S1).

\section{Life-history traits}

We used information on species traits related to body size, life cycle, number of generations/year, locomotion, and feeding habits. These traits were selected to represent key 
characteristics of the species and because information on those traits was available for the majority of the taxa included in the analyses ( 89 out of the 99 taxa observed in the Llyn Brianne data set; Appendix S1: Table S1). Taxa excluded from the trait-based analyses included mostly locally rare coleopterans as well as Chironomidae and Oligochaeta for which there was no specific identification. The effect of excluding these taxa from the trait analyses was likely minimal, since Chironomidae and Oligochaeta were consistently observed over the years. Additional traits were not considered in the analyses to avoid the exclusion of other taxa. Traits were coded using the fuzzy approach to assign each taxon an affinity for a particular trait category (Chevenet et al. 1994). These affinities were standardized between 0 and 1 to reflect the relative strength of association of each taxon for a given trait category. Information was gathered from published sources (Tachet et al. 2000) and from the comprehensive online database on the ecology of freshwater organisms (Schmidt-Kloiber and Hering 2015; database available online) ${ }^{7}$

\section{Statistical analyses}

From the macroinvertebrate assemblage data, we calculated taxonomic richness, functional diversity, and taxonomic and functional homogenization using multiple approaches.

We examined temporal trends in taxonomic richness and functional diversity and homogenization at three spatial extents: local scale (within stream), metacommunity scale (the 10 streams across Llyn Brianne), and regional scale (the 58 streams from the Wales-wide monitoring). Functional diversity was expressed as functional dispersion (FDis), which is mathematically independent from species richness, using the FD package in R (Laliberté and Legendre 2010). Fuzzy correspondence analysis (FCA) was used to ordinate taxa on the functional trait space; this method is recommended for fuzzy-coded traits (Chevenet et al. 1994). The first four axes (explaining $>50 \%$ of variation) were used to construct the distance matrix for the calculation of FDis. Functional dispersion was considered a valid method to represent the overall functional diversity of the assemblages, as we did not examine changes in individual trait representation or functional groups.

To assess overall changes in community composition through time (temporal $\beta$-diversity), for each stream we plotted the Jaccard distance between each year and the first year of the survey (1984), as in Dornelas et al. (2014). Using the same approach, we also examined patterns in temporal $\beta$-diversity at the metacommunity scale combining the 10 streams.

Taxonomic homogenization was investigated by plotting mean pairwise Jaccard distance between streams over time (spatial $\beta$-diversity). A decline in distance through time would indicate that streams are becoming increasingly similar to each other in taxonomic composition. Although Jaccard is a widely used measure of $\beta$-diversity, we also estimated homogenization using two additional measures based on the multiplicative approach $(\beta=\Upsilon / \alpha)$ (Whittaker

\footnotetext{
${ }^{7}$ www.freshwaterecology.info
}

1960) and the multi-site Sorensen distance (Baselga 2013). These all provided similar results (Appendix S1: Fig. S2) and we here show only those based on the Jaccard distance.

We examined functional homogenization in two ways. First, consistent with the taxonomic approach, we assessed homogenization by plotting functional spatial $\beta$-diversity among streams over time calculating pairwise functional distance (Jaccard) using the functional.beta.pair function in the R package betapart (Villeger et al. 2014). Second, we assessed whether assemblage level specialization declined over time (e.g., Clavel et al. 2011). We estimated specialization using two independent and complementary approaches to measure species niche breadth.

First, using trait information, we calculated trait specialization (TS) as the specialization of species according to a priori information about life history traits. For each taxon and trait, we calculated trait specialization based on the Simpson index as in Mondy and Usseglio-Polatera (2014), defined as $\mathrm{TS}_{t i}=$ $\Sigma^{k} c_{t i k}{ }^{2}$, where $\mathrm{TS}_{\mathrm{ti}}$ is the specialization for trait $i$ of taxon $t$, and $c_{t i k}$ is the relative use of category $k$ of trait $i$ by taxon $t$. TS values were then normalized to account for the different number of categories among traits (Appendix S1 and Appendix S1: Table S1). For each taxon, values from each trait were averaged to express the taxon specialization, such that specialized taxa scored high if they had a strong affinity for one or few categories within traits, while generalists scored low and had even affinity for all categories within traits. Community specialization was expressed as the mean of the constituent species. Species niche breadth was thus expressed on a continuous scale avoiding subjective definition of specialists and generalists. To examine eventual differences among traits in their contribution to overall specialization, we assessed temporal patterns in TS separately for each trait.

The second estimate of specialization reflected species' observed environmental tolerance and was calculated using the distribution of taxa at the regional scale in conjunction with physical-chemical characteristics of the water, including nutrients, $\mathrm{pH}$, alkalinity, and major ions (Appendix S1). We calculated species niche breadth using the OMI ordination (Outlying Mean Index; Dolédec et al. 2000), which provides a variance term defining the range of environmental variables over which the species was observed. This value can be considered to reflect the realized niche breadth of the species, which we call tolerance (larger tolerance = larger realized niche). We calculated community tolerance as the mean across the constituent species (more details on the estimation of different nice breadths are given in Appendix S1).

To test if the observed community specialization (according to both niche breadth measures) changed through time, we used a null model where specialization was expressed as deviation from what would be expected given the observed richness in each stream each year. To do this, we randomized niche-breadth values across taxa (999 times), but kept community matrices identical. Deviations were expressed as $z$-score $=($ mean observed - mean simulated $) /(\mathrm{SD}$ simulated $)$, from which we assessed temporal trends. This approach represents a conservative test of the non-randomness of temporal changes in community specialization, which controls for changes in taxonomic richness.

We examined temporal trends in all diversity and homogenization measures using linear Ordinary Least Square 
(OLS) regressions. Temporal autocorrelation in the time series was then assessed by verifying the occurrence of serial correlation in the regression residuals (Cowpertwait and Metcalfe 2009). No autocorrelation were observed, except for the case of taxonomic homogenization (trends in pairwise Jaccard distance), which we accounted for by applying a Generalized Least Square (GLS) autoregressive model of order $=1$. Examination of trends by means of non-parametric Kendall-Tau provided identical results (not shown). Because the 10 streams in Llyn Brianne differ in water physical-chemical characteristics, we also used mixed-models to assess whether stream identity influenced the results when included as a random factor.

Finally, we calculated taxon-specific background probability of local extinction $\left(p_{\mathrm{e}}\right)$ and immigration $\left(p_{\mathrm{i}}\right)$ from the occurrence time series of each taxon across the 10 streams as in Gotelli and Taylor (1999):

$$
\begin{aligned}
p_{\mathrm{e}}= & n \text { for sites occupied in time }(t) \text { that were unoccupied } \\
& \text { at time }(t+1) / n \text { and } \\
p_{\mathrm{i}}= & n \text { for sites unoccupied in time }(t) \text { that were occupied } \\
& \text { at time }(t+1) / n .
\end{aligned}
$$

Extinction and immigration probabilities were calculated for 71 taxa, excluding those with four or fewer occurrences across the streams in the Llyn Brianne metacommunity, for which probabilities could not be estimated (Gotelli and Taylor 1999). OLS regressions were used to investigate the relationship of $p_{\mathrm{e}}$ and $p_{\mathrm{i}}$ with species trait specialization.

\section{RESUlTS}

Taxonomic richness ( $\alpha$-diversity) did not change over the last $30 \mathrm{yr}$ at any scale, including local (within stream), metacommunity (combining 10 streams in the Llyn Brianne catchment) (Fig. 1a), and regional scale (Wales; Fig. 1b), but there was considerable year-to-year variation. Similarly, there was no directional change at any scale in functional diversity as FDis (Fig. 1a, b; reddish line). However, temporal $\beta$-diversity patterns revealed that assemblage composition within streams changed systematically through time (Fig. 1c, $R^{2}=0.42 ; P<0.001$ ), with an average slope across streams of 0.006 , indicating a turnover of $\sim 6 \%$ of species per decade (Jaccard distance is bounded between 0 and 1; see also Dornelas et al. 2014). At the metacommunity scale, this trend was not apparent (Fig. 1c; dashed line).

There was no signal of on-going taxonomic homogenization across the Llyn Brianne streams, and a GLM model controlling for temporal autocorrelation showed that mean pairwise compositional dissimilarity (spatial $\beta$-diversity) between streams remained stable, despite some decline in 1987-1989 (Fig. 2a). Assessment of functional homogenization using an equivalent approach based on mean pairwise functional spatial $\beta$-diversity (Jaccard distance) between streams also revealed no directional change through time, despite a dip in 2003 (Fig. 2b). Patterns were similar at the regional scale, where both taxonomic and functional pairwise dissimilarity were stable over the study period (Appendix S1: Fig. S3).

In contrast, community trait specialization (TS) changed significantly. At the beginning of the study, the deviation of the mean community TS did not differ from a random distribution of niche sizes across the observed taxa ( $z$-score). Through time, however, TS values became progressively smaller than expected with an overall negative trend indicating a non-random decline in the proportion of narrow niche species (Fig. 3a; $R^{2}=0.28 ; P=0.004$ ). These included, among others, the trichopteran Chaetopteryx villosa, the plecopteran Amphinemura sulcicollis, and the flatworms Phagocata vitta and Crenobia alpina (the latter now extinct at Llyn Brianne; Durance and Ormerod 2010). Inclusion of stream identity as a random factor using a mixed model provided near identical results (data not shown), and hence only results from the simple OLS models are shown. Examination of temporal patterns for individual traits revealed that the observed trend in mean specialization was mostly dictated by significant declines in feeding habit and locomotion specialization (Appendix S1: Fig. S4). However, size specialization showed a weak opposite trend increasing through time (Appendix S1: Fig. S4). For the Llyn Brianne streams, which included abundance data, we also examined TS patterns ( $z$-scores) weighted by log-abundance. A systematic decline in specialization was evident, albeit weaker $\left(R^{2}=0.17\right.$; Appendix S1: Fig. S5), while no temporal trends in taxonomic diversity (Shannon index) were evident at either local or metacommunity scale (Appendix S1: Fig. S5).

When we calculated community niche breadth from species observed environmental tolerance (community tolerance) using the OMI ordination, the observed temporal trend in the $z$-score indicated an increase in the relative representation of taxa with wider niches (larger tolerance; Fig. $3 \mathrm{a} ; R^{2}=0.4$; $P<0.001)$. The two independent measures of community specialization were correlated negatively $\left(r_{\mathrm{sp}}=-0.3\right.$; $P=0.01)$; this is expected, as TS is a measure of species specialization, while tolerance represents niche width.

Trends in trait specialization were no longer apparent when the 10 streams were pooled to represent the whole Llyn Brianne metacommunity $(P=0.3)$. This suggests that no actual extirpation of specialist taxa occurred in the system, but rather there was a decline in their mean occurrence across streams. Similarly, at the regional scale, there was no significant decline in the $z$-scores of community TS and tolerance (Fig. 3b), although statistical power was limited to the three snapshot observations over the $30 \mathrm{yr}$. Similar patterns were evident when representing the regional scale by pooling all 58 streams (data not shown).

When we calculated the probability of species local extinction and immigration to examine possible mechanisms behind the decline in community TS across the 10 Llyn Brianne streams, local extinction probability was unrelated to trait specialization (Fig. 4a). However, local recolonization probability was negatively (but non-linearly) associated with species trait specialization (Fig 4b; $R^{2}=0.36 ; P<0.0001$ ). This correlation was evident only for the overall trait specialization and not for specialization according to individual traits (Appendix S1: Fig. S6).

\section{Discussion}

The data used in this study represent one of the longest available time series of macroinvertebrates dynamics in lotic systems anywhere in the world, linked uniquely to trait 

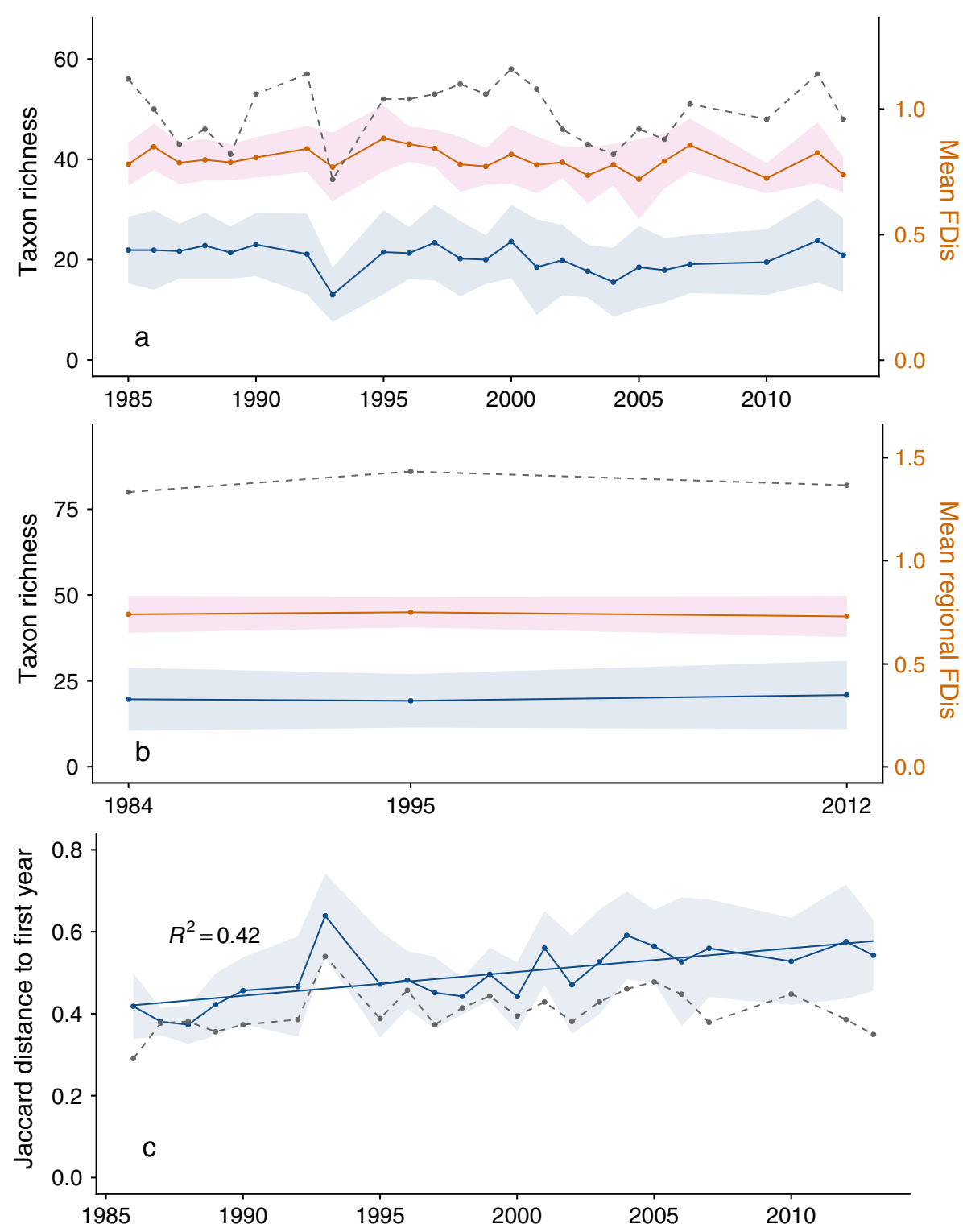

FIG. 1. Temporal biodiversity patterns across scales. (a) Temporal patterns in mean local richness (blue line), metacommunity-scale richness (dashed line), and mean functional diversity as FDis (reddish line) across the 10 Llyn Brianne, Wales, streams. (b) Temporal patterns at the regional scale (58 streams across Wales) are shown with the same color code. No temporal trends are evident. (c)Trends in mean temporal $\beta$-diversity at the local scale (blue line) and metacommunity scale (dashed line) are shown as Jaccard distance relative to the initial year. These indicate systematic changes in composition at the local scale, but not at the metacommunity scale (combining the 10 Llyn Brianne streams). Shaded areas represent SD.

information and regional data collected over the same period. Examination of commonly used taxonomic and functional diversity metrics suggested that overall biodiversity remained stable over the last three decades and across different spatial extents. Moreover, temporal trends in both taxonomic and functional spatial $\beta$-diversity provided no sign of on-going homogenization over this period. However this apparent stasis masked evident compositional changes that resulted in the non-random decline in mean community specialization. We discuss the implications of these findings for the assessment of biodiversity change in general.

Patterns of local $\alpha$-diversity at Llyn Brianne and across Wales were consistent with recent global meta-analyses indicating no directional change in local diversity in the last $\sim 30$ yr (Vellend et al. 2013, Dornelas et al. 2014). The relatively large year-to-year variation that we observed is unlikely to reflect sampling error, given the consistent quality-checked method employed (Bradley and Ormerod 2002), and can be attributed to loss and recovery of richness metrics following climatic fluctuations in the region, including a major amplification of the North Atlantic Oscillation in the late 1980s (Bradley and Ormerod 2001). This suggests that resource availability and general environmental conditions remained within the tolerance of the majority of species over the course of the time series. Only the flatworm Crenobia alpina was lost from the Llyn Brianne catchment over the study period, reflecting drought and fluctuating prey abundance in the early 1990s (Durance and Ormerod 2010). Wider analyses across 

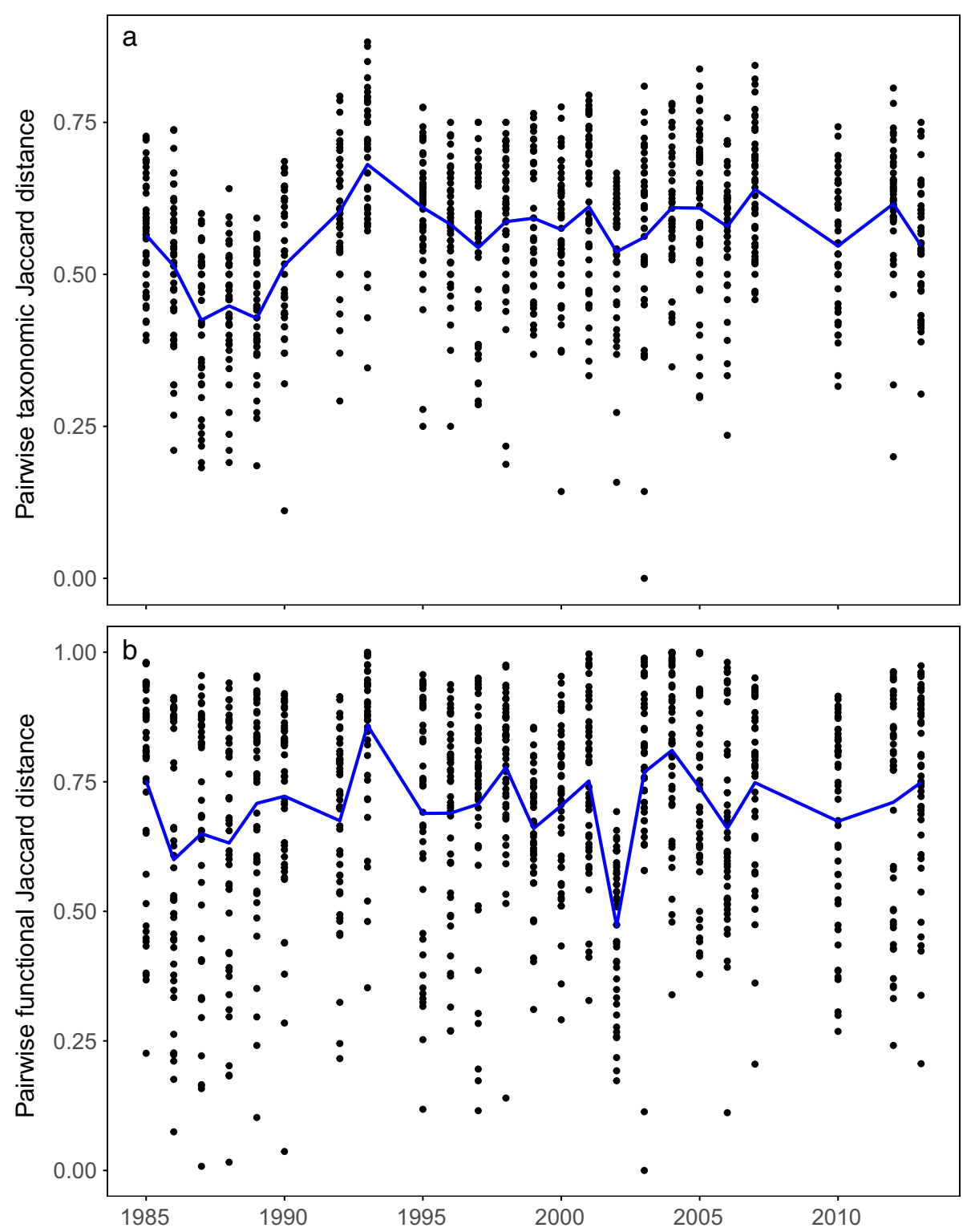

FIG. 2. Taxonomic and functional dissimilarity through time. Plots of mean pairwise (a) taxonomic and (b) functional spatial $\beta$-diversity (Jaccard) across the Llyn Brianne streams through time. Each dot is a pairwise comparison. Mean taxonomic distance shows a dip in 19871989, but appears stable thereafter with no evident trend. Mean functional distance also appears stable over time. The dip in 2003 occurs during hot, dry conditions experienced in the study area in 2003.

England and Wales over the last two to three decades showed benthic invertebrate richness increasing, although these effects owe much to improved water quality in urban regions (Vaughan and Ormerod 2014). Similar increasing trends were observed throughout France, owing to the recovery of many pollution-sensitive taxa (Van Looy et al. 2016). In rural Welsh rivers, effects of sediment regime and land use changes have had localized negative effects on invertebrate diversity and trait composition, but at lower altitudes and in more agricultural systems than those studied here (Larsen and Ormerod 2010). In the Llyn Brianne streams and across upland Wales, in fact, macroinvertebrate functional diversity also appeared stable, in line with patterns in taxonomic richness.

Our results provided no evidence for either taxonomic or functional homogenization at any scale. Interestingly, there was a visible dip in functional spatial $\beta$-diversity in 2003, a particularly hot and dry year across Europe (García-Herrera et al. 2010). Reports of biotic homogenization are numerous in freshwater systems, especially among river fish communities in Nearctic and Palearctic catchments that were heavily influenced by the introduction of nonnative species (e.g., Olden 2006, Villeger et al. 2011). Moreover, across European river basins, translocation of species has caused functional homogenization to exceed taxonomic homogenization by sixfold (Villeger et al. 2014). Assessments of homogenization in freshwater invertebrate assemblages are much scarcer but, in the UK, invasions by freshwater invertebrates were confined largely to the lowland waters of the south and east (e.g., Aldridge et al. 2004) rather than in the upland north and west, as also indicated by our results. 

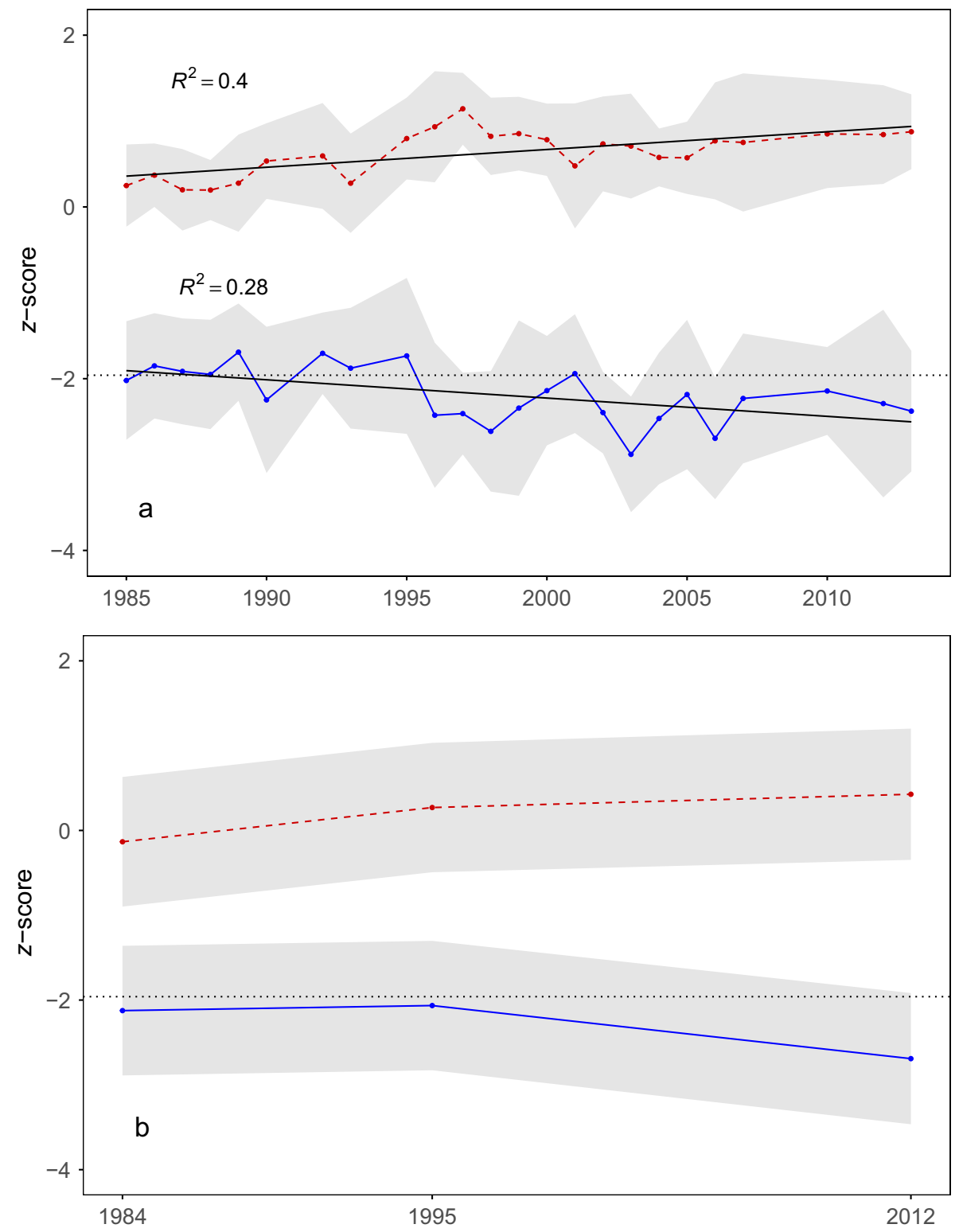

FIG. 3. Temporal trends in community niche breadth measures. Trends in the deviation ( $z$-score) of community trait specialization (TS; blue line), and community tolerance (red dashed line) from what expected given the observed taxonomic richness. (a) Trends of mean values across 10 Llyn Brianne streams (straight lines) were significant for both indices, indicating a decline in mean community specialization. (b) Trends at the regional scale (58 streams across Wales) were not significant, but appear consistent with what was observed locally. The dashed horizontal line at $z$-score $=-1.96$ represents the threshold under which values are below expectation. For TS in panel a, values at the beginning of the census period were not different than expected, but declined below expectation progressively. Shaded areas represent SD.

Although functional homogenization is generally expressed as changes in functional spatial $\beta$-diversity, a decline in the representation of specialist species within assemblages has also been interpreted as a form of homogenization (e.g., Clavel et al. 2011). However, this approach has been criticized when specialization is simply expressed in terms of habitat use (a response trait; Gosselin 2012) as this bears little information about an organisms' function. To overcome this limitation, we estimated taxon specialization using two independent measures of niche breadth, which provided complementary estimates based on a priori trait information as well as observed species environmental tolerance. In contrast to taxonomic and functional metrics based on $\alpha$-diversity and spatial $\beta$-diversity, patterns in mean specialization in the Llyn Brianne catchment indicated a systematic decline in mean community niche breadth (or alternatively an increase in mean tolerance). These patterns were consistent when analyses included abundance data from the Llyn Brianne streams, where a systematic decline in abundance-weighted trait specialization was accompanied by relatively stable taxonomic diversity at both local and metacommunity scale.

The fact that such decline was not discernible from functional $\alpha$-diversity and spatial $\beta$-diversity patterns suggests that functional homogenization can occur in at least two distinct ways: loss of functions (e.g., a decrease in functional 

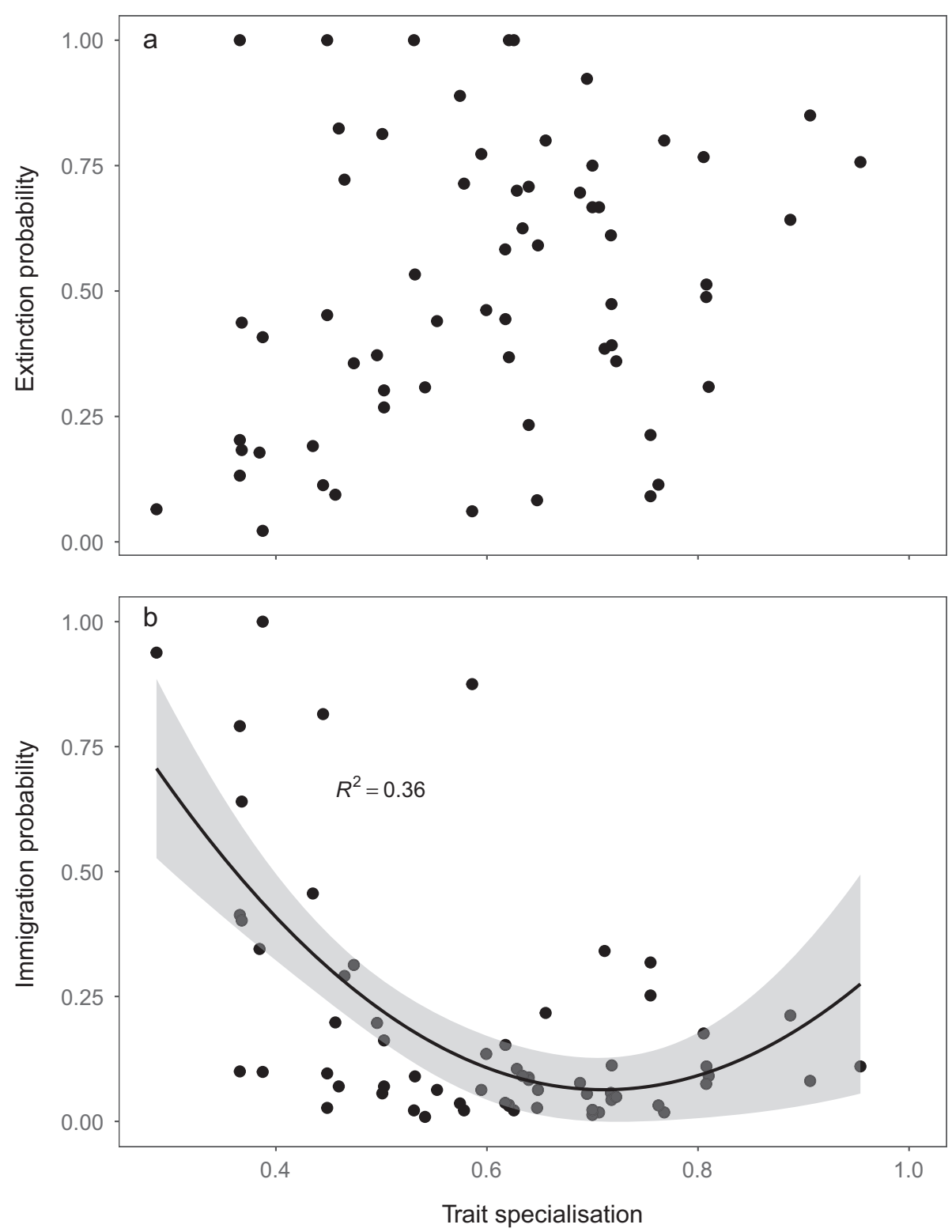

FIG. 4. Relationship between rates of local (a) extinction and (b) colonization and species trait specialization. The observed probability of local extinction and immigration was calculated from species occurrence time-series across 10 Llyn Brianne streams. Trait specialization was not related to extinction probability, but showed negative and non-linear relationship with immigration $\left(R^{2}=0.36 ; P<0.001\right)$.

space) and the losses of specialists with narrow niches. The extent to which a decline in narrow-niche species translates into decreased functional diversity (or spatial $\beta$-diversity) depends on the functional distinctness of the taxa involved. Species with narrow ecological niches are not necessarily functionally distinct from the others. In our study system, functional originality (the average pairwise distance of a taxon from the others in functional space) was not correlated to species trait specialization $\left(R^{2}=0.05\right)$. To further clarify this point, in Appendix S1: Fig. S7, we provide a schematic illustration of how changes in $\alpha$-, $\beta$-, and $\gamma$-diversity can be largely decoupled from changes in functional diversity, while different functional attributes, such as diversity and mean niche breadth, can also respond differently to the same underlying change.
We are aware of few recent studies that used a similar approach to ours in estimating invertebrate species specialization (e.g., Mondy and Usseglio-Polatera 2014, Dolédec et al. 2017, Floury et al. 2017). In contrast to our observations, Floury et al. (2017) reported an increase in feeding specialization across France, which was also accompanied by positive trends in overall functional diversity. In their study, taxon specialization was estimated exclusively from feeding traits, while we calculated specialization from multiple traits, including size, life cycle, locomotion, and feeding habits. Nonetheless, specialization based on feeding habits also showed a declining trend in our study streams. In addition, as in Mondy and Usseglio-Polatera (2014), we found that trends in specialization can differ across different traits, perhaps reflecting the influence of distinct environmental 
drivers (Appendix S1: Fig. S4). However, assessing patterns in individual traits was beyond the scope of the study and we conservatively expressed species specialization based on all included traits. Nonetheless, these results suggest that future work on this system could benefit from a detailed examination of changes in individual traits.

Overall, taxa from our data set that scored high on trait specialization showed little flexibility in their reproductive biology, and were generally limited in their feeding and locomotion strategies, as commonly observed in specialists species (e.g., Verberk et al. 2010). One possible explanation for the reduction in the occupancy of specialists through time, therefore, is a combination of higher local extinction rates coupled with lower re-colonization rates. Analyses of the background probability of local extinction and immigration of each taxon suggest that while specialists and generalists had the same chance of becoming locally "extinct," specialists were apparently limited in their ability to recolonize a site. This, in turn, led to the progressive decline in their occurrence in the Llyn Brianne catchment. However, attributing changes in community specialization to a particular taxon or group is not straightforward in this case, since specialization was expressed as a continuous variable that reflected the overall composition of the assemblages. That is, while species at the "extreme ends" of the specialization continuum might contribute more to the observed changes, the mean specialization was a property of the entire assemblage.

An additional inference from these findings is that different processes might regulate local extinction and immigration dynamics in benthic invertebrates. This effect is known from other long-term studies of different taxonomic groups where, for instance, factors regulating colonization of habitat fragments in butterflies differed between specialist and generalists, while extinction rates did not differ (FernandezChacon et al. 2014). Similarly, the long-term dynamic of forest birds can be predicted well from niche-based limitations on species immigration (Carnicer et al. 2008).

An important aspect of the present study is that the local decline in assemblage specialization through time was associated with mean temporal change in composition across streams $(<6 \%$ of species per decade) that was lower than the global mean observed across multiple taxa in a recent metaanalysis ( $\sim 10 \%$ of species per decade; Dornelas et al. 2014). Interestingly, metacommunity-scale temporal composition (combining the 10 streams) did not show significant change through time. Together these findings indicate that, while there was some redistribution of taxa across streams (leading to localized decline in community specialization), no major turnover occurred at the rivers system scale. This is in agreement with results from the null models showing no apparent decline in specialization at the metacommunity scale. These results corroborate the observation that these Llyn Brianne streams represents a metacommunity connected by dispersal (Masters et al. 2007).

An appraisal of the drivers underpinning this level of compositional turnover in our system goes beyond the scope of the present study, because of the challenges of assessing environmental trends across such an array of upland stream types varying in acid-base status and land use. Nevertheless, candidate hypotheses that could explain trends across the whole Welsh upland region include changes in prevailing westerly weather (Bradley and Ormerod 2001), changing temperature (Durance and Ormerod 2007), variation in hydrologic regimes (Durance and Ormerod 2010), progressive recovery from acidification and localized land management (Ormerod and Durance 2009). The effect of these changes have still to be fully resolved but, in total, could disproportionally affect taxa with lower dispersal ability and tolerance to environmental stochasticity, thereby leading to a progressive decline in their occurrence over time.

In showing how biodiversity change can occur locally despite the apparent stability deduced from multiple taxonomic and functional indices of $\alpha$-diversity and spatial $\beta$-diversity, our study contributes to the current debate about biodiversity change by addressing two key points (Gosselin 2012, Thomas 2013, Hillebrand et al. 2017, Cardinale et al. 2018, Primack et al. 2018). First, the issue of spatial scale has been central in the debate about biodiversity change (e.g., Sax and Gaines 2003), and most of the discussion on the absence of a net decline in local richness focused on whether this was the consequence of global declines coupled with regional increases (Thomas 2013). This has led to a growing interest in assessing long-term diversity changes across spatial scales (e.g., Keil et al. 2012, Bernhardt-Roemermann et al. 2015), but studies in freshwaters remain rare. Here, we used two independent data sets collected at different spatial extents but with identical methods to show how non-random biodiversity decline can be accompanied by stable richness at both local and regional scales.

The fact that richness estimates are insufficient to understand biodiversity change is well known (e.g., Lindenmayer et al. 2015), although univariate diversity measures remain the principal tool for biodiversity assessment and monitoring (Hillebrand et al. 2017). This leads to our second key point of the utility of including species trait information when examining biodiversity change and erosion. However, there is little agreement regarding the definition and assessment of functional homogenization, expressed as either a loss of specialist species or loss of functional $(\beta)$ diversity (Gosselin 2012). Here, we combine these approaches using the same set of traits. The results highlighted how different homogenization measures can deviate depending on whether species functional distinctness or niche breadth is considered. Moreover, an independent estimate of species niche breadth (based on occurrences at the regional scale), provided consistent results and correlated well with niche measures based on life history traits, thus supporting the use of similar trait specialization indices for examining functional changes (Mondy and Usseglio-Polatera 2014, Floury et al. 2017).

Besides these methodological considerations, measurement of functional diversity is frequently used to understand how changes in diversity relate to ecosystem function (Cadotte et al. 2011). The fact that we did not observe any decline in functional $\alpha$-diversity and spatial $\beta$-diversity implies a likely stability in ecosystem functioning over the study period. However, specialist species are often more effective at consuming and converting resources in a given habitat type than generalists (e.g., Finke and Snyder 2008), so that overall ecosystem functioning could be disproportionally affected by declining specialization. With growing evidence for stable and even increasing trends in local and 
regional richness across ecosystem types (e.g., Dornelas et al. 2014, Batt et al. 2017, Jones et al. 2017), our results highlight the need to examine the extent to which taxonomic patterns mask important functional changes. We advocate further long-term assessments that extend beyond simple taxonomic and functional diversity measures to appraise whether other, hidden changes in biodiversity resulting from the losses of specialists are common.

\section{ACKNOWLedgments}

S. Larsen (sDiv fellowship) and J. Chase were supported by the German Centre for Integrative Biodiversity Research (iDiv) HalleJena-Leipzig funded by the German Research Foundation (FZT 118). S. Larsen was also supported by funding from the European Union's Horizon 2020 Research and Innovation Programme under grant agreement No. 748969 with an Individual MSC Fellowship. Many individuals contributed to the collection of these data over the last 35 yr. The Llyn Brianne Stream Observatory is currently funded by the Esmée Fairbairn Foundation and SJO/ID are funded by the NERC Duress NE/J014818/1 and the EU MARS project under the 7th Framework Programme (Contract No. 603378). We thank Mark Urban, Jarrett Byrnes, Yog Sothoth, and an anonymous reviewer for their comments on the manuscript.

\section{Literature Cited}

Aldridge, D. C., P. Elliott, and G. D. Moggridge. 2004. The recent and rapid spread of the zebra mussel (Dreissena polymorpha) in Great Britain. Biological Conservation 119:253-261.

Baiser, B., and J. L. Lockwood. 2011. The relationship between functional and taxonomic homogenization: functional and taxonomic homogenization. Global Ecology and Biogeography 20:134-144

Barnosky, A. D., et al. 2011. Has the Earth's sixth mass extinction already arrived? Nature 471:51-57.

Baselga, A. 2013. Multiple site dissimilarity quantifies compositional heterogeneity among several sites, while average pairwise dissimilarity may be misleading. Ecography 36:124-128.

Batt, R. D., J. W. Morley, R. L. Selden, M. W. Tingley, and M. L. Pinsky. 2017. Gradual changes in range size accompany long-term trends in species richness. Ecology Letters 20:1148-1157.

Bernhardt-Roemermann, M., et al. 2015. Drivers of temporal changes in temperate forest plant diversity vary across spatial scales. Global Change Biology 21:3726-3737.

Bradley, D. C., and S. J. Ormerod. 2001. Community persistence among stream invertebrates tracks the North Atlantic Oscillation. Journal of Animal Ecology 70:987-996.

Bradley, D. C., and S. J. Ormerod. 2002. Evaluating the precision of kick-sampling in upland streams for assessments of long-term change: the effects of sampling effort, habitat and rarity. Archiv für Hydrobiologie 155:199-221.

Brown, J., S. Ernest, J. Parody, and J. Haskell. 2001. Regulation of diversity: maintenance of species richness in changing environments. Oecologia 126:321-332.

Butchart, S. H. M., et al. 2010. Global biodiversity: indicators of recent declines. Science 328:1164-1168.

Cadotte, M. W., K. Carscadden, and N. Mirotchnick. 2011. Beyond species: functional diversity and the maintenance of ecological processes and services. Journal of Applied Ecology 48:1079-1087.

Cardinale, B. J., A. Gonzalez, G. R. H. Allington, and M. Loreau. 2018. Is local biodiversity declining or not? A summary of the debate over analysis of species richness time trends Biological Conservation 219:175-183.

Carnicer, J., L. Brotons, D. Sol, and M. de Cáceres. 2008. Random sampling, abundance-extinction dynamics and niche-filtering immigration constraints explain the generation of species richness gradients. Global Ecology and Biogeography $17: 352-362$
Cassey, P., T. M. Blackburn, J. L. Lockwood, and D. F. Sax. 2006. A stochastic model for integrating changes in species richness and community similarity across spatial scales. Oikos 115:207-218.

Chase, J. M., and T. M. Knight. 2013. Scale-dependent effect sizes of ecological drivers on biodiversity: why standardized sampling is not enough. Ecology Letters 16:17-26.

Chevenet, F., S. Doléadec, and D. Chessel. 1994. A fuzzy coding approach for the analysis of long-term ecological data. Freshwater Biology 31:295-309.

Clavel, J., R. Julliard, and V. Devictor. 2011. Worldwide decline of specialist species: toward a global functional homogenization? Frontiers in Ecology and the Environment 9:222-228.

Cowpertwait, P. S., and A. V. Metcalfe. 2009. Introductory time series with R. Springer, Berlin, Germany.

Dolédec, S., D. Chessel, and C. Gimaret-Carpentier. 2000. Niche separation in community analysis: a new method. Ecology 81:2914-2927.

Dolédec, S., J. Tilbian, and N. Bonada. 2017. Temporal variability in taxonomic and trait compositions of invertebrate assemblages in two climatic regions with contrasting flow regimes. Science of the Total Environment 599-600:1912-1921.

Domisch, S., M. B. Araújo, N. Bonada, S. U. Pauls, S. C. Jähnig, and P. Haase. 2013. Modelling distribution in European stream macroinvertebrates under future climates. Global Change Biology 19:752-762.

Dornelas, M., N. J. Gotelli, B. McGill, H. Shimadzu, F. Moyes, C. Sievers, and A. E. Magurran. 2014. Assemblage time series reveal biodiversity change but not systematic loss. Science 344:296-299.

Dudgeon, D., et al. 2006. Freshwater biodiversity: importance, threats, status and conservation challenges. Biological Reviews of the Cambridge Philosophical Society 81:163-182.

Durance, I., and S. J. Ormerod. 2007. Climate change effects on upland stream macroinvertebrates over a 25 -year period. Global Change Biology 13:942-957.

Durance, I., and S. J. Ormerod. 2010. Evidence for the role of climate in the local extinction of a cool-water triclad. Journal of the North American Benthological Society 29:1367-1378.

Elahi, R., M. I. O’Connor, J. E. K. Byrnes, J. Dunic, B. K. Eriksson, M. J. S. Hensel, and P. J. Kearns. 2015. Recent trends in localscale marine biodiversity reflect community structure and human impacts. Current Biology 25:1938-1943.

Eskildsen, A., L. G. Carvalheiro, W. D. Kissling, J. C. Biesmeijer, O. Schweiger, and T. T. Høye. 2015. Ecological specialization matters: long-term trends in butterfly species richness and assemblage composition depend on multiple functional traits. Diversity and Distributions 21:792-802.

Fernandez-Chacon, A., C. Stefanescu, M. Genovart, J. D. Nichols, J. E. Hines, F. Paramo, M. Turco, and D. Oro. 2014. Determinants of extinction-colonization dynamics in Mediterranean butterflies: the role of landscape, climate and local habitat features. Journal of Animal Ecology 83:276-285.

Finke, D. L., and W. E. Snyder. 2008. Niche partitioning increases resource exploitation by diverse communities. Science 321:14881490.

Floury, M., Y. Souchon, and K. V. Looy. 2017. Climatic and trophic processes drive long-term changes in functional diversity of freshwater invertebrate communities. Ecography 41:209-218.

García-Herrera, R., J. Díaz, R. M. Trigo, J. Luterbacher, and E. M. Fischer. 2010. A review of the European summer heat wave of 2003. Critical Reviews in Environmental Science and Technology 40:267-306.

Gosselin, F. 2012. Improving approaches to the analysis of functional and taxonomic biotic homogenization: beyond mean specialization. Journal of Ecology 100:1289-1295.

Gotelli, N. J., and C. M. Taylor. 1999. Testing metapopulation models with stream-fish assemblages. Evolutionary Ecology Research $1: 835-845$.

Harrison, S. P., E. S. Gornish, and S. Copeland. 2015. Climate-driven diversity loss in a grassland community. Proceedings of the National Academy of Sciences USA 112:8672-8677. 
Hillebrand, H., et al. 2017. Biodiversity change is uncoupled from species richness trends: consequences for conservation and monitoring. Journal of Applied Ecology 55:169-184.

Jones, S. K., J. Ripplinger, and S. L. Collins. 2017. Species reordering, not changes in richness, drives long-term dynamics in grassland communities. Ecology Letters 20:1556-1565.

Keil, P., et al. 2012. Patterns of beta diversity in Europe: the role of climate, land cover and distance across scales: multiscale patterns of beta diversity in Europe. Journal of Biogeography 39:14731486

Laliberté, E., and P. Legendre. 2010. A distance-based framework for measuring functional diversity from multiple traits. Ecology 91:299-305.

Larsen, S., and S. J. Ormerod. 2010. Combined effects of habitat modification on trait composition and species nestedness in river invertebrates. Biological Conservation 143:2638-2646.

Lindenmayer, D., W. Blanchard, P. Tennant, P. Barton, K. Ikin, A. Mortelliti, S. Okada, M. Crane, and D. Michael. 2015. Richness is not all: How changes in avian functional diversity reflect major landscape modification caused by pine plantations. Diversity and Distributions 21:836-847.

Masters, Z., I. Peteresen, A. G. Hildrew, and S. J. Ormerod. 2007. Insect dispersal does not limit the biological recovery of streams from acidification. Aquatic Conservation: Marine and Freshwater Ecosystems 17:375-383.

McGill, B. J., M. Dornelas, N. J. Gotelli, and A. E. Magurran. 2015 Fifteen forms of biodiversity trend in the Anthropocene. Trends in Ecology and Evolution 30:104-113.

Mondy, C. P., and P. Usseglio-Polatera. 2014. Using fuzzy-coded traits to elucidate the non-random role of anthropogenic stress in the functional homogenization of invertebrate assemblages. Freshwater Biology 59:584-600.

Monnet, A.-C., F. Jiguet, C. N. Meynard, D. Mouillot, N. Mouquet, W. Thuiller, and V. Devictor. 2014. Asynchrony of taxonomic, functional and phylogenetic diversity in birds. Global Ecology and Biogeography 23:780-788.

Olden, J. D. 2006. Biotic homogenization: a new research agenda for conservation biogeography. Journal of Biogeography 33:20272039 .

Ormerod, S. J., and I. Durance. 2009. Restoration and recovery from acidification in upland Welsh streams over 25 years. Journal of Applied Ecology 46:164-174.

Ormerod, S. J., K. R. Wade, and A. S. Gee. 1987. Macro-floral assemblages in upland Welsh streams in relation to acidity, and their importance to invertebrates. Freshwater Biology 18:545557.

Pimm, S. L., N. C. Jenkins, R. Abell, T. M. Brooks, J. L. Gittelman, N. P. Joppa, P. H. Raven, C. M. Roberts, and J. P. Sexton. 2014. The biodiversity of species and their rates of extinction, distribution, and protection. Science 334:1246752.

Poff, N. L. 1997. Landscape filters and species traits: towards mechanistic understanding and prediction in stream ecology. Journal of the North American Benthological Society 16:391-409.

Primack, R. B., A. J. Miller-Rushing, R. T. Corlett, V. Devictor, D. M. Johns, R. Loyola, B. Maas, R. J. Pakeman, and L. Pejchar.
2018. Biodiversity gains? The debate on changes in local- vs global-scale species richness Biological Conservation 219:A1-A3.

Ricciardi, A., and J. B. Rasmussen. 1999. Extinction rates of North American freshwater fauna. Conservation Biology 13:1220-1222.

Sax, D. F., and S. D. Gaines. 2003. Species diversity: from global decreases to local increases. Trends in Ecology and Evolution 18:561-566.

Schmidt-Kloiber, A., and D. Hering. 2015. www.freshwaterecology. info - An online tool that unifies, standardises and codifies more than 20,000 European freshwater organisms and their ecological preferences. Ecological Indicators 53:271-282.

Sonnier, G., S. E. Johnson, K. L. Amatangelo, D. A. Rogers, and D. M. Waller. 2014. Is taxonomic homogenization linked to functional homogenization in temperate forests? Global Ecology and Biogeography 23:894-902.

Supp, S. R., and S. K. Ernest. 2014. Species-level and communitylevel responses to disturbance: a cross-community analysis. Ecology 95:1717-1723.

Tachet, H., P. Richoux, and M. Bournaud. 2000. Invertébrés d'Eau Douce. Systématique, biologie, écologie. CNRS, Paris, France.

Thomas, C. D. 2013. Local diversity stays about the same, regional diversity increases, and global diversity declines. Proceedings of the National Academy of Sciences USA 110:19187-19188.

Townsend, C. R., and A. G. Hildrew. 1994. Species traits in relation to a habitat templet for river systems. Freshwater Biology 31:265275.

Van Looy, K., M. Floury, M. Ferréol, M. Prieto-Montes, and Y. Souchon. 2016. Long-term changes in temperate stream invertebrate communities reveal a synchronous trophic amplification at the turn of the millennium. Science of the Total Environment 565:481-488.

Vaughan, I. P., and S. J. Ormerod. 2014. Linking interdecadal changes in British river ecosystems to water quality and climate dynamics. Global Change Biology 20:2725-2740.

Vellend, M., L. Baeten, I. H. Myers-Smith, S. C. Elmendorf, R. Beausejour, C. D. Brown, P. De Frenne, K. Verheyen, and S. Wipf. 2013. Global meta-analysis reveals no net change in localscale plant biodiversity over time. Proceedings of the National Academy of Sciences USA 110:19456-19459.

Verberk, W. C. E. P., G. van der Velde, and H. Esselink. 2010. Explaining abundance-occupancy relationships in specialists and generalists: a case study on aquatic macroinvertebrates in standing waters. Journal of Animal Ecology 79:589-601.

Villeger, S., S. Blanchet, O. Beauchard, T. Oberdorff, and S. Brosse. 2011. Homogenization patterns of the world's freshwater fish faunas. Proceedings of the National Academy of Sciences USA 108:18003-18008

Villeger, S., G. Grenouillet, and S. Brosse. 2014. Functional homogenization exceeds taxonomic homogenization among European fish assemblages: change in functional beta-diversity. Global Ecology and Biogeography 23:1450-1460.

Whittaker, R. H. 1960. Vegetation of the Siskiyou Mountains, Oregon and California. Ecological Monographs 30:279-338.

\section{SUPPORTING INFORMATION}

Additional supporting information may be found in the online version of this article at http://onlinelibrary.wiley.com/doi/10.1002/ecy. 2213/suppinfo 